\title{
A ADOÇÃO DO SISU E A EVASÃO NA UNIVERSIDADE FEDERAL DE UBERLÂNDIA
}

\author{
ADOPCIÓN DE SISU Y LA EVASIÓN EN LA UNIVERSIDAD FEDERAL \\ UBERLÂNDIA
}

\section{THE ADOPTION OF SISU AND EVASION AT THE FEDERAL UNIVERSITY OF UBERLÂNDIA}

\author{
João Paulo Gomes BARBOSA ${ }^{1}$ \\ Lucio Antonio PORTILHO ${ }^{2}$ \\ Gilberto Jose MIRANDA ${ }^{3}$ \\ Marcelo TAVARES ${ }^{4}$
}

RESUMO: O principal objetivo do trabalho foi verificar a evolução do percentual de alunos evadidos nos anos antes (2006 a 2010) e depois (2011 a 2014) da adoção do Sistema de Seleção Unificada (SISU) na Universidade Federal de Uberlândia (UFU). Trata-se de uma pesquisa documental. Os dados relativos à evasão foram obtidos com a Pró-reitoria de Graduação (PROGRAD) da instituição. Na primeira parte da verificação das informações, foi realizada a organização dos dados relativos aos alunos evadidos da UFU no período analisado, sendo tratadas 15.088 ocorrências. Em seguida os dados foram classificados e sintetizados. Posteriormente foi aplicado o teste estatístico binomial. As áreas de Ciências Sociais Aplicadas, Ciências Humanas e Ciências Exatas e da Terra foram as que apresentam os maiores percentuais de alunos evadidos. Ao analisar as médias por área, verifica-se que as áreas Ciências Agrárias, Ciências Biológicas, Engenharias, Ciências Exatas e da Terra e Ciências da Saúde apresentam aumento significativos nos percentuais de alunos evadidos após o SISU. Enquanto as áreas de Ciências Humanas, Linguística, Letras e Artes e Ciências Sociais Aplicadas apresentaram reduções significativas nos percentuais de alunos evadidos.

PALAVRAS-CHAVE: SISU. Evasão. UFU. Ensino superior. Educação.

RESUMEN: La evasión es un fenómeno que afecta a las instituciones de educación superior. Ése es el contexto que se encuadra. El objetivo principal del estudio fue determinar el porcentaje del comportamiento de los estudiantes de abandono en los años anteriores (2006 a 2010) y después (2011-2014) de la adopción del Sistema de Selección Unificada (SISU) en la Universidade Federal de Uberlândia (UFU). Se trata de una investigación documental. Los datos sobre la evasión se obtuvieron con el Decanato de Graduación (PROGRAD) de la institución. En la primera parte de la verificación de las informaciones se realizó una organización de los datos para los estudiantes evadidos de la UFU no período examinado, tratadas 15.088 ocurrencias. En seguida los datos fueron clasificados y sintetizados. Posteriormente se aplicó el ensayo estadístico binomial. Las áreas de Ciencias Aplicadas

\footnotetext{
${ }^{1}$ Mestre em Ciências Contábeis UFU, Brasil. Email: joaopaulo@ufu.br

${ }^{2}$ Mestre em Ciências Contábeis UFU, Brasil. Email: lucio@ufu.br

${ }^{3}$ Doutor em Controladoria e Contabilidade (USP) - Professor do Programa de Pós-Graduação em Ciências Contábeis da Universidade Federal de Uberlândia - UFU. E-mail: gilbertojm@ufu.br

4 Doutor em Agronomia - Professor do Programa de Pós-Graduação em Ciências Contábeis da Universidade Federal de Uberlândia - UFU. E-mail: mtavares@ufu.br.
} 
Sociales, Humanidades y Ciencias Exactas y de la Tierra son los que tienen los más altos porcentajes de deserción de los estudiantes. Mediante el análisis de la media de la zona, parece que las áreas de Ciencias Agrícolas, Ciencias Biológicas, Ingeniería, Ciencias Exactas y de la Tierra y Ciencias de la Salud presentan aumento significativo en el porcentaje de estudiantes de abandono después de SISU. Mientras que las áreas de Humanidades, Lingüística, Letras y Artes y las Ciencias Sociales mostraron reducciones significativas en el porcentaje de alumnos evadidos.

PALABRAS CLAVE: SISU. Evasión. UFU. Educación superior. Educación.

ABSTRACT: The main objective of this study was to determine the percentage of the behavior of dropout students in the years before (2006-2010) and after (2011-2014) the adoption of the Brazilian Unified Selection System (SISU) in the Universidade Federal de Uberlândia (UFU). This is a documentary research. The Data about evasion were obtained with the Dean of Graduate (PROGRAD). In the first part of the verification of information it was held the organization of data on dropout students of the UFU in the period analyzed, and treated 15,088 occurrences. Then the data were classified and summarized and after the binomial statistical test was applied. In the results, the Applied Social Sciences, Humanities and Exact Sciences and Earth areas were those with the highest percentages of dropout students. By analyzing the average by areas, the Agricultural Sciences, Biological Sciences, Engineering, Exact Sciences and Earth and Health Sciences areas presents significant increase in the percentage of dropout students after the SISU. While the Humanities, Linguistics, Literature and Arts and Social Sciences areas showed significant reductions in the percentage of dropout students.

KEYWORDS: SISU. Dropout. UFU. Higher education. Education.

\section{Introdução}

Sun Tzu (544-496 a. C.), em a Arte da Guerra, revela este diálogo: "Se um general não é corajoso, será incapaz de resolver dúvidas e arquitetar grandes planos”. Da mesma maneira, um correto olhar do administrador público sobre indicadores que afetam direta ou indiretamente os recursos financeiros de uma Instituição de Ensino Superior (IES) pública é um comportamento corajoso esperado. Nesse sentido, desvelar, controlar e acompanhar os indicadores de evasão em uma IES é tarefa de uma administração competente e comprometida com a instituição (CHIAVENATO, 2003). Esse indicador deve ser analisado e considerado nos balizadores de diretrizes e ações de planejamento que serão definidos no Plano de Desenvolvimento Institucional (PDI). Pois,

O Plano de Desenvolvimento Institucional - PDI, elaborado para um período de cinco anos, é o documento que identifica a Instituição de Ensino Superior (IES), no que diz respeito à sua filosofia de trabalho, à missão a que se propõe, às diretrizes pedagógicas que orientam 
suas ações, à sua estrutura organizacional e às atividades acadêmicas que desenvolve e/ou que pretende desenvolver. (BRASIL, 2002, p. 2).

Essas ações e diretrizes têm por objetivo propiciar condições de obtenção de recursos para financiar investimentos em obras, compra de equipamentos para o ensino e a pesquisa, distribuição de bolsas de estudos e alimentação, abertura de novos cursos, etc. Tais condições apresentaram-se mais evidentes devido a ações e incentivos governamentais (no sentido de expansão do ensino superior) que foram e estão sendo implementados (MOEHLECKE; CATANI, 2006). Sem um correto tratamento do índice de evasão dos alunos, tais ações ficam comprometidas negativamente, afetando transferências de recursos da União para a Universidade e consequentemente afetando programas e ações adotados no PDI.

Dentro das diretrizes do MEC, se encontra como nova política, o Sistema de Seleção Unificada (SISU). Criado a partir da Portaria Normativa MEC n 2, de 26 de janeiro de 2010 e alterado pela Portaria Normativa MEC no 21, de 5 de novembro de 2012, o SISU oportunizou às IES públicas uma forma de aporte de recursos ao aderirem ao projeto (BRASIL, 2013a).

Trata-se de uma mudança muito importante, pois no primeiro semestre de 2013 houve mais de 1,9 milhão de inscritos no SISU em todo o país que disputaram cerca de 129 mil vagas de 3.752 diferentes cursos em 101 universidades públicas e institutos federais de educação (BRASIL, 2013b). No entanto, a introdução do SISU não só trouxe perspectiva de recursos, mas também uma forma de ingresso totalmente nova, possibilitando a entrada de estudantes de várias regiões do país, muitos deles com residência em regiões bem distantes das IES em que foram aprovados.

Nessa ótica, tem se tornado senso comum no meio universitário a ideia de que o SISU teria aumentado as taxas de evasão nas IES públicas, muito embora ainda careça de estudos científicos sobre o fenômeno. A justificativa é de que os alunos ingressantes por meio do SISU poderiam deixar os cursos em locais distantes de seus lares em função do retorno para regiões mais próximas, principalmente se tiverem condições de ingressar em outras Universidades.

Diante desse cenário, no presente trabalho tem-se a seguinte questão de pesquisa: os percentuais de alunos evadidos por área de conhecimento na Universidade Federal de Uberlândia (UFU) tiveram alterações significativas após a adesão ao SISU? Diante desse questionamento, o objetivo principal do trabalho é observar se a evasão da UFU se alterou após a adesão ao SISU, ou seja, de 2011 em diante. Também foram 
estabelecidos os seguintes objetivos específicos: (i) verificar se o fenômeno da evasão ocorre com mais frequência em determinada área do conhecimento e curso; (ii) analisar como a evasão entre os estudantes da UFU se comporta em relação a variáveis demográficas, como: gênero, turno e forma de evasão.

Este estudo se justifica pela escassez de trabalhos sobre a evasão nas escolas de ensino superior públicas, dado o contexto atual da entrada das Universidades Públicas Federais no SISU, bem como, a pouca divulgação de dados sobre evasão por parte dos órgãos do governo federal, responsáveis pela análise e controle do nível da qualidade da educação superior no país.

No tocante à UFU, as contribuições poderão ser ainda maiores, uma vez que os número relacionados a evasões e jubilamentos tem aumentado nos anos de 2013, 2014 e 2015, com 563 abandonos e 701 jubilamentos em 2013, 1.599 abandonos e 220 jubilamentos em 2014 e 553 abandonos e 1.765 jubilamentos no ano de 2015 (NOGUEIRA, 2015).

\section{Referencial teórico}

\section{O Fenômeno Evasão}

A evasão está associada à evolução do aluno durante a sua vida acadêmica. Ela ocorre nos vários ciclos do aprendizado, passando pelo ensino fundamental, ensino médio e superior. É um fenômeno social complexo, definido como a interrupção no ciclo de estudos e consequente abandono da instituição onde o indivíduo desenvolvia suas atividades educacionais (GAIOSO, 2005). Pesquisas de diferentes autores apontam que os índices de evasão alcançam até 50\% dos alunos matriculados, sendo maior o impacto para nos primeiros períodos dos cursos superiores (BARDAGI E HUTZ, 2009).

Em geral a evasão está atrelada a três tipos de ocorrências: $i$ ) a evasão do curso: definida como a saída definitiva do aluno de seu curso de origem, sem concluí-lo, causada por situações diversas, como: abandono (deixar de matricular-se), desistência (oficial), transferência ou nova opção (mudança de curso), exclusão por norma institucional. (BRASIL, 1997); ii) evasão da instituição: quando o aluno abandona a instituição de ensino em que está, podendo ou não mudar de curso; iii) e a evasão do sistema: quando o aluno desiste do ensino superior, abandonando por completo os 
estudos universitários (MERCURI; POLYDORO, 2004). Esses três tipos caracterizadores da evasão afetam significativamente os resultados dos sistemas educacionais, gerando perdas e desperdícios dos recursos (públicos ou privados) investidos, sem o devido retorno. Nesse sentido, para Silva Filho et al. (2007), a evasão é uma fonte de ociosidade de docentes, servidores, equipamentos e espaço físico.

Ainda nessa vertente, o relatório BRASIL (1997) apresenta alguns fatores que têm peso decisório no âmbito do tema evasão no ensino superior. Tais fatores são ordenados da seguinte forma: em primeiro lugar, aqueles que se relacionam ao próprio estudante; em segundo, os relacionados ao curso e à instituição e; os fatores socioculturais e econômicos externos (BRASIL, 1997, p. 136). Desta forma, é possível perceber que não somente ao estudante recai a responsabilidade sobre a evasão, mas esta deve ser considerada apenas uma variável no conjunto.

Para Furtado e Alves (2012), as instituições de ensino superior não estão fazendo a gestão adequada dos cursos existentes e nem planejando adequadamente a abertura de novos cursos. A preocupação com a evasão deve ser um elemento sine qua non nas políticas norteadoras das condições oferecidas pela instituição, tanto no projeto pedagógico quanto na mensuração da qualidade do ensino.

O grupo elaborador do relatório BRASIL (1997), responsável pela análise das causas e consequências da evasão no ensino de graduação nas IES públicas, registra a necessidade das instituições estabelecerem e cumprirem normas eficazes de permanência dos alunos até a diplomação. Nesse sentido, a comissão especial destaca a necessidade de comprometimento dos Reitores e Pró-Reitores de Graduação com a divulgação das informações sobre evasão e permanência, às vezes não tão boas, mas que fazem parte da transparência de toda gestão pública.

No intuito de orientar os administradores das IES - Reitores e Pró-Reitores, consta no relatório BRASIL (1997) um alerta sobre os fatores intrínsecos e extrínsecos relacionados ao indivíduo, que podem pesar no momento da decisão de abandonar o curso, sendo eles: (i) os relativos às habilidades de estudo, decorrentes da má formação escolar anterior; (ii) os econômicos, decorrentes da incompatibilidade entre a vida acadêmica e as exigências do mundo do trabalho; (iii) os psicológicos, relacionados à personalidade; (iv) os vinculados à escolha precoce da profissão; (v) os relacionados a dificuldades pessoais de adaptação à vida universitária; (vi) os decorrentes do desencanto ou da desmotivação dos alunos com cursos escolhidos em segunda ou terceira opção, revelando a desinformação a respeito da natureza dos cursos; (vii) os 
decorrentes de dificuldades na relação ensino aprendizagem, traduzidas em reprovações constantes ou na baixa frequência às aulas; (viii) o amadurecimento, levando a descoberta de novos interesses que levam à realização de novo vestibular (BRASIL; 1997).

Assim, avaliar não somente as variáveis que envolvem o aluno, mas também voltar o olhar para as variáveis relacionadas à instituição é fator fundamental para a diminuição da ocorrência do fenômeno da evasão.

\section{O Sistema de Seleção Unificada (SISU)}

O SISU foi criado pela Portaria Normativa $\mathrm{n}^{\circ}$ 2, de 26 de janeiro de 2010, que posteriormente, foi revogada pela Portaria Normativa $\mathrm{n}^{\mathrm{o}} 21$, de 5 de novembro de 2012, a qual instituiu e regulamentou o Sistema de Seleção Unificada (BRASIL, 2010). Conceitualmente o SISU é um sistema informatizado gerenciado pelo Ministério da Educação (MEC) para seleção de candidatos a vagas em cursos de graduação disponibilizadas pelas instituições públicas de ensino superior dele participantes. Os candidatos às vagas utilizam a nota do Enem como única fase de seu processo seletivo. A seleção é feita pelo Sistema com base na nota obtida pelo candidato.

É importante ressaltar que algumas instituições adotam notas mínimas para inscrição em determinados cursos. Nesse caso, no momento da inscrição, se a nota do candidato não for suficiente para concorrer àquele curso, o sistema emitirá uma mensagem com esta informação (BRASIL, 2015).

Como já comentado anteriormente, com o SISU, as chances de ingresso no ensino superior em uma universidade pública aumentaram para muitos estudantes, principalmente para aqueles que residiam em locais desprovidos de instituições públicas. Certamente o número de matrículas ociosas deve ter sido reduzido; por outro lado, a evasão pode ter aumentado. A esse respeito, a própria UFU, investigada neste estudo, argumenta que as evasões cresceram consideravelmente nos últimos anos, em virtude de o aluno poder escolher várias instituições no país num mesmo processo seletivo por meio do SISU. De acordo com informações da Diretoria de Controle da UFU, constantes no Anuário 2014, ano base 2013, ao optar por outra universidade "os alunos entram em nosso cadastro como desistentes oficiais" (UFU, 2014), compondo assim a evasão da instituição. 


\section{Metodologia}

\section{Classificação da Pesquisa}

Quanto aos objetivos, esta pesquisa classifica-se como descritiva, pois visa a compreensão e o mapeamento da evolução da evasão na UFU nos anos de 2006 a 2014, observando se a evasão da UFU se alterou após a adesão ao SISU, ou seja, de 2011 em diante.

Quanto à abordagem do problema, a pesquisa é de natureza quantitativa, pois é utilizado o teste estatístico binomial para análise dos dados. Segundo Beuren et al. (2009, p. 92), a análise quantitativa “caracteriza-se pelo emprego de instrumentos estatísticos, tanto na coleta, quanto no tratamento dos dados".

Quanto ao delineamento, trata-se de uma pesquisa documental, uma vez que são utilizados dados relativos à evasão obtidos junto à Pró-Reitoria de Graduação da Universidade. Nesse sentido, Gil (2002) afirma que o procedimento de coleta documental é um tratamento analítico que se dá em documentos arquivados em órgãos públicos e privados.

\section{Procedimentos de Coleta de dados}

Para a o desenvolvimento deste trabalho, os dados relativos aos alunos evadidos, ingressantes e egressos da UFU, foram obtidos junto a Diretoria de Registro e Controle Acadêmico (DIRAC) da UFU, setor sob a responsabilidade de Pró-Reitoria de Graduação (PROGRAD). A coleta de dados foi realizada por meio de levantamento e planilhamento de informações constantes no banco de dados do Sistema de Informações para o Ensino (SIE) da UFU nos meses de abril e maio de 2015.

Na primeira parte da verificação das informações, foi realizada a organização dos dados relativos aos alunos evadidos da UFU no período de 2006 a 2014. Nesta etapa, foram tratadas 15.088 ocorrências. Em seguida foram organizadas informações referentes aos dados de alunos ingressantes neste mesmo período para que pudessem ser definidas as principais variáveis trabalhadas na pesquisa (gênero, período de evasão, tipo de formação, turno e forma de evasão). O software utilizado para a organização dos dados e aplicação dos testes foi o Microsoft Office Excel 2007. 


\section{Análise dos Dados}

Para verificar se houve diferença significativa entre os percentuais de evasão antes e após a adoção do SISU na UFU, foram realizados os testes binomiais, considerando as seguintes hipóteses:

$\mathrm{H}_{0}$ : O percentual de alunos evadidos da UFU não se alterou após a adoção do SISU.

$\mathrm{H}_{1}$ : O percentual de alunos evadidos da UFU se alterou após a adoção do SISU.

As análises estatísticas, bem como seus resultados, foram realizadas no Microsoft Office Excel 2007. Utilizou-se o teste binomial para verificar a existência de associação entre as variáveis qualitativas para os resultados apresentados, considerando o nível de significância (p-valor) em 0,05. Nesse caso, quando o p-valor for menor ou igual a 0,05 , será rejeitada a hipótese $\mathrm{H}_{0}$. Por outro lado, quando o p-valor for maior que $0,05 \mathrm{H}_{0}$ não serárejeitada.

Após os testes, os resultados são discutidos à luz da literatura revisada.

\section{Resultados e análises}

A somatória de alunos evadidos nos anos anteriores ao SISU na UFU foi de $6.056(40,14 \%)$. Após a adoção do SISU pela UFU o total de alunos evadidos foi de $9.032(59,86 \%)$, totalizando as 15.088 (100\%) ocorrências encontradas no banco de dados de alunos evadidos da instituição. Nesse banco de dados não são considerados os alunos formados, matriculados e ingressantes, somente os evadidos.

Assim, verifica-se que houve um maior percentual de alunos evadidos após a adoção do SISU do que antes, quando a UFU utilizava o vestibular clássico como forma de ingresso. Ao se aplicar o teste binomial para esta proporção, o p-valor desta distribuição foi de 0,000 , ou seja, o percentual total de alunos evadidos se alterou significativamente após a adoção do SISU pela UFU.

Na Tabela 1, são apresentados os resultados do teste binomial, considerando o percentual de alunos evadidos da UFU para as variáveis evasão geral (evadidos geral) e gênero, confrontadas por área de conhecimento do CNPq. Foram 
considerados os anos antes da adoção do SISU (2006 a 2010) e os anos posteriores à adoção do SISU (2011 a 2014).

Tabela1: Teste Binomial para percentual de alunos evadidos antes e após a adoção do SISU, para a variável evasão geral e por gênero

\begin{tabular}{|c|c|c|c|c|c|c|c|c|c|}
\hline & \multicolumn{3}{|c|}{ EVASÃO GERAL } & \multicolumn{3}{|c|}{ FEMININO } & \multicolumn{3}{|c|}{ MASCULINO } \\
\hline $\begin{array}{c}\text { ÁREA DO } \\
\text { CONHECIMENTO }\end{array}$ & $\begin{array}{c}\% \\
\text { ANTES } \\
\text { DO } \\
\text { SISU }\end{array}$ & $\begin{array}{c}\% \\
\text { DEPOIS } \\
\text { DO } \\
\text { SISU }\end{array}$ & $\begin{array}{l}\text { P- } \\
\text { valor }\end{array}$ & $\begin{array}{c}\% \\
\text { ANTES } \\
\text { DO } \\
\text { SISU }\end{array}$ & $\begin{array}{c}\% \\
\text { DEPOIS } \\
\text { DO } \\
\text { SISU }\end{array}$ & $\begin{array}{l}\text { P- } \\
\text { valor }\end{array}$ & $\begin{array}{c}\% \\
\text { ANTES } \\
\text { DO } \\
\text { SISU }\end{array}$ & $\begin{array}{c}\% \\
\text { DEPOIS } \\
\text { DO } \\
\text { SISU }\end{array}$ & $\begin{array}{l}\text { P- } \\
\text { valor }\end{array}$ \\
\hline Ciências Agrárias & 2,54 & 3,41 & 0,002 & 2,39 & 3,20 & 0,048 & 2,66 & 3,61 & 0,018 \\
\hline Ciências Biológicas & 3,34 & 5,85 & 0,000 & 4,52 & 7,67 & 0,000 & 2,40 & 4,09 & 0,000 \\
\hline Engenharias & 11,71 & 13,63 & 0,001 & 5,87 & 9,18 & 0,000 & 3,37 & 4,11 & 0,089 \\
\hline $\begin{array}{c}\text { Ciências Exatas e } \\
\text { da Terra }\end{array}$ & 17,42 & 22,60 & 0,000 & 12,97 & 16,99 & 0,000 & 20,95 & 28,01 & 0,000 \\
\hline Ciências Humanas & 21,48 & 19,53 & 0,003 & 24,74 & 23,10 & 0,115 & 18,91 & 16,09 & 0,001 \\
\hline $\begin{array}{c}\text { Linguística, Letras } \\
\text { e Artes }\end{array}$ & 12,68 & 8,95 & 0,000 & 17,86 & 11,80 & 0,000 & 26,80 & 19,98 & 0,000 \\
\hline $\begin{array}{c}\text { Ciências Sociais } \\
\text { Aplicadas }\end{array}$ & 25,76 & 20,19 & 0,000 & 24,44 & 20,42 & 0,000 & 16,33 & 17,92 & 0,064 \\
\hline Ciências da Saúde & 5,07 & 5,85 & 0,041 & 7,21 & 7,65 & 0,500 & 8,58 & 6,20 & 0,000 \\
\hline
\end{tabular}

Fonte: Elaborado pelos autores

Considerando a análise do p-valor para a evasão geral apresentada na Tabela 1, é possível verificar que após a adoção do SISU houve mudanças significativas nos percentuais de alunos evadidos para as áreas Ciências Agrárias, Ciências Biológicas, Engenharias, Ciências Exatas e da Terra, Ciências Humanas, Linguística, Letras e Artes, Ciências Sociais Aplicadas e Ciências da Saúde. Desta forma rejeita-se a hipótese $\mathrm{H}_{0}$.

No entanto, quando se observa as médias por área, verifica-se que as áreas Ciências Agrárias, Ciências Biológicas, Engenharias, Ciências Exatas e da Terra e Ciências da Saúde, que são as áreas tradicionalmente mais concorridas nos processos seletivos, nota-se que elas apresentaram aumento significativos nos percentuais de alunos evadidos após o SISU. Já as áreas de Ciências Humanas, Linguística, Letras e Artes e Ciências Sociais Aplicadas apresentaram reduções significativas nos percentuais de alunos evadidos.

Observando os resultados estatísticos para o gênero feminino, presentes na Tabela 1, nota-se comportamento muito semelhante à evasão geral. A única diferença se refere à área de Ciências Humanas. Ou seja, nesta área, entre as mulheres não houve diferença significativa entre os percentuais de estudantes evadidos antes e após a adoção ao SISU. 
Por fim, ainda observando os dados apresentados na Tabela 1, considerando a variável gênero masculino, verifica-se a mesma tendência. No entanto, as áreas de Engenharia e Ciências Sociais Aplicadas não apresentaram diferença significativa entre os percentuais de estudantes evadidos antes e após a adoção ao SISU.

O turno em que o aluno estuda também foi considerado como um fator potencial na decisão de evadir-se da universidade, de acordo com os estudos de Cunha et al. (2015), tendo em vista que a muitos estudantes trabalham para sobreviver e custear seus estudos, e optam, dessa maneira, por contingência de adequação, por cursos noturnos. A Tabela 2 apresenta os resultados do teste binomial realizado para o percentual de alunos evadidos considerando o turno no qual o aluno estudava, sendo as variáveis integral, noturno e matutino por área do conhecimento.

Tabela2: Teste Binomial para percentual de alunos evadidos antes e após a adoção do SISU por turno

\begin{tabular}{|c|c|c|c|c|c|c|c|c|c|}
\hline \multirow[b]{2}{*}{$\begin{array}{c}\text { ÁREA DO } \\
\text { CONHECIMENTO }\end{array}$} & \multicolumn{3}{|c|}{ INTEGRAL } & \multicolumn{3}{|c|}{ NOTURNO } & \multicolumn{3}{|c|}{ MATUTINC } \\
\hline & $\begin{array}{c}\% \\
\text { ANTES } \\
\text { DO } \\
\text { SISU } \\
\end{array}$ & $\begin{array}{c}\% \\
\text { DEPOIS } \\
\text { SISU }\end{array}$ & $\begin{array}{l}\text { P- } \\
\text { valor }\end{array}$ & $\begin{array}{c}\% \\
\text { ANTES } \\
\text { DO } \\
\text { SISU } \\
\end{array}$ & $\begin{array}{c}\% \\
\text { DEPOIS } \\
\text { SISU }\end{array}$ & P-valor & $\begin{array}{c}\% \\
\text { ANTES } \\
\text { DO } \\
\text { SISU } \\
\end{array}$ & $\begin{array}{c}\% \\
\text { DEPOIS } \\
\text { SISU }\end{array}$ & $\begin{array}{l}\text { P- } \\
\text { valor }\end{array}$ \\
\hline Ciências Agrárias & 5,63 & 6,47 & 0,145 & 0,00 & 0,00 & - & 0,00 & 0,00 & - \\
\hline Ciências Biológicas & 6,07 & 7,92 & 0,003 & 2,12 & 6,18 & 0,000 & 0,00 & 0,00 & - \\
\hline Engenharias & 25,93 & 25,87 & 0,954 & 0,00 & 0,00 & - & 0,00 & 0,00 & - \\
\hline $\begin{array}{c}\text { Ciências Exatas e } \\
\text { da Terra }\end{array}$ & 25,35 & 26,02 & 0,522 & 21,27 & 32,53 & 0,000 & 0,00 & 0,00 & - \\
\hline Ciências Humanas & 0,77 & 0,99 & 0,334 & 37,19 & 32,86 & 0,004 & 67,59 & 59,88 & 0,001 \\
\hline $\begin{array}{c}\text { Linguística, Letras } \\
\text { e Artes }\end{array}$ & 8,08 & 3,40 & 0,000 & 19,68 & 11,13 & 0,000 & 21,61 & 19,37 & 0,226 \\
\hline $\begin{array}{l}\text { Ciências Sociais } \\
\text { Aplicadas }\end{array}$ & 16,93 & 18,22 & 0,160 & 19,74 & 17,31 & 0,046 & 10,80 & 20,75 & 0,000 \\
\hline Ciências da Saúde & 11,23 & 11,10 & 0,861 & 0,00 & 0,00 & - & 0,00 & 0,00 & - \\
\hline
\end{tabular}

Fonte: Elaborado pelos autores

A Tabela 2 mostra que quando se observa apenas os alunos matriculados no turno integral, as diferenças significativas de percentuais de evasão antes e após a adesão ao SISU aparecem apenas nas áreas de Ciências Biológicas e Linguística, Letras e Artes. Ou seja, para estes cursos a hipótese $\mathrm{H}_{1}$ não foi rejeitada. No entanto, na área de Linguística, Letras e Artes, o percentual de alunos evadidos após a adoção do SISU diminuiu, enquanto na área de Ciências Biológicas houve aumento. 
Considerando o turno noturno, as áreas de Ciências Biológicas, Ciências Exatas e da Terra, Ciências Humanas, Ciências Sociais Aplicadas e Linguística, Letras e Artes apresentaram p-valor menor que 0,05 , ou seja, tiveram $\mathrm{H}_{0}$ rejeitada, pois o percentual de alunos evadidos se alterou na UFU, após a adoção do SISU, nestas áreas. Seguindo a tendência já apontada na evasão geral, as áreas de Ciências Biológicas e Ciências Exatas e da Terra tiveram aumento significativo nos percentuais de evasão, enquanto as áreas de Ciências Humanas, Ciências Sociais Aplicadas e Linguística, Letras e Artes, tiveram redução. No turno noturno não são oferecidos cursos para as áreas Ciências Agrárias, Ciências da Saúde e Engenharias na UFU.

No turno matutino são oferecidos cursos nas áreas Ciências Humanas, Ciências Sociais Aplicadas e Linguística, Letras e Artes. Nas áreas de Ciências Humanas e Ciências Sociais Aplicadas o percentual de alunos evadidos se alterou na UFU, após a adoção do SISU, mas na área de Linguística, Letras e Artes não houve alterações significativas. Na Tabela 3 são apresentados os resultados do teste binomial, considerando o percentual de evadidos por tipo de evasão. De acordo com dados do anuário da UFU (2014), para se calcular o total da evasão são somados os casos do tipo jubilamento, desistência, abandono, transferência, falecimento e desligamento. Entretanto, considerando a análise sob o ponto de vista do percentual de evadidos antes e após a adoção do SISU, serão analisados apenas os tipos: abandono, desistente e jubilamento, pois as demais não apresentam relação direta com o SISU. 
Tabela 3: Teste Binomial para percentual de alunos evadidos antes e após a adoção do SISU por tipo de evasão

\begin{tabular}{|c|c|c|c|c|c|c|c|c|c|}
\hline \multirow[b]{2}{*}{$\begin{array}{c}\text { ÁREA DO } \\
\text { CONHECIMENTO }\end{array}$} & \multicolumn{3}{|c|}{ ABANDONO } & \multicolumn{3}{|c|}{ DESISTENTES } & \multicolumn{3}{|c|}{ JBILAMENTO } \\
\hline & $\begin{array}{c}\% \\
\text { ANTES } \\
\text { DO } \\
\text { SISU } \\
\end{array}$ & $\begin{array}{c}\% \\
\text { DEPOIS } \\
\text { SISU }\end{array}$ & $\begin{array}{l}\text { P- } \\
\text { valor }\end{array}$ & $\begin{array}{c}\% \\
\text { ANTES } \\
\text { DO } \\
\text { SISU }\end{array}$ & $\begin{array}{c}\% \\
\text { DEPOIS } \\
\text { SISU }\end{array}$ & $\begin{array}{l}\text { P- } \\
\text { valor }\end{array}$ & $\begin{array}{c}\% \\
\text { ANTES } \\
\text { DO } \\
\text { SISU } \\
\end{array}$ & $\begin{array}{c}\% \\
\text { DEPOIS } \\
\text { SISU }\end{array}$ & P-valor \\
\hline Ciências Agrárias & 6,17 & 1,93 & 0,000 & 3,62 & 4,11 & 0,364 & 2,48 & 2,30 & 0,856 \\
\hline Ciências Biológicas & 6,65 & 5,15 & 0,021 & 4,49 & 7,38 & 0,000 & 2,79 & 2,30 & 0,616 \\
\hline Engenharias & 28,41 & 7,77 & 0,000 & 14,19 & 15,91 & 0,083 & 10,22 & 10,49 & 0,885 \\
\hline $\begin{array}{c}\text { Ciências Exatas e } \\
\text { da Terra }\end{array}$ & 18,23 & 19,36 & 0,292 & 23,89 & 26,07 & 0,068 & 12,07 & 22,70 & 0,000 \\
\hline Ciências Humanas & 0,84 & 26,88 & 0,000 & 18,43 & 14,73 & 0,000 & 38,39 & 24,15 & 0,000 \\
\hline $\begin{array}{c}\text { Linguística, Letras } \\
\text { e Artes }\end{array}$ & 8,85 & 12,74 & 0,000 & 8,17 & 5,79 & 0,000 & 11,46 & 12,88 & 0,493 \\
\hline $\begin{array}{c}\text { Ciências Sociais } \\
\text { Aplicadas }\end{array}$ & 18,55 & 20,29 & 0,110 & 20,93 & 19,80 & 0,304 & 21,67 & 21,33 & 0,895 \\
\hline Ciências da Saúde & 12,30 & 5,87 & 0,000 & 6,28 & 6,22 & 0,933 & 0,93 & 3,84 & 0,009 \\
\hline
\end{tabular}

Fonte: Elaborado pelos autores

Ao analisar o tipo de evasão "abandono", alguns aspectos chamam a atenção. O primeiro deles é que somente as áreas Ciências Exatas e da Terra e Ciências Sociais Aplicadas não tiveram alterações significativas após a adoção do SISU. Também se nota que as áreas Ciências Agrárias, Ciências Biológicas, Engenharias e Ciências da Saúde tiveram quedas significativas nos percentuais de alunos evadidos, principalmente nos cursos de Engenharia, que caíram de 28,41\% para 7,77. Já as áreas de Ciências Humanas e Linguística, Letras e Artes tiveram aumentos significativos após a adoção ao SISU. Chama a atenção a diferença apresentada pela área de Ciências Humanas, que teve um aumento de 26,04\%. A esse respeito é importante lembrar que o Conselho de Graduação da UFU aprovou a resolução CONGRAD 02/2013, impondo regras mais rígidas nos casos do jubilamento, coincidindo com o período após a adoção do SISU. No entanto, essa variante aparenta não ter sido afetada por essa resolução, uma vez que os aumentos relativos ao jubilamento não se apresentaram tão elevados nas outras áreas.

Com relação à evasão por desistência, demonstrada na Tabela 3, o percentual de alunos evadidos teve alterações significativas na UFU, após a adoção do SISU, em Ciências Biológicas, Ciências Humanas e Linguística, Letras e Artes. Sendo que a primeira área teve aumento significativo e as outras duas quedas significativas nos percentuais de alunos evadidos.

Por fim, para a evasão por jubilamento, apresentada na Tabela 3, somente os cursos das áreas Ciências da Saúde, Ciências Exatas e da Terra e Ciências Humanas 
apresentaram diferenças significativas após a adoção ao SISU, sendo que a área de Ciências Exatas e da Terra e Ciências da Saúde apresentaram aumentos significativos nos percentuais de alunos evadidos, enquanto a área de Ciências Humanas apresentou queda.

\section{Considerações finais}

O trabalho buscou sintetizar e organizar informações quantitativas sobre o comportamento percentual de alunos evadidos na Universidade Federal de Uberlândia, a fim de observar as variações nas proporções de evasão ocorridas após a adoção do Sistema de Seleção Unificado para ingresso ao ensino superior - SISU. O processo de entrada da UFU no SISU iniciou-se a partir de 2011 e se mantém até o presente momento. Os ingressos ocorrem no primeiro semestre letivo de cada ano.

Pode-se constatar que as áreas de Ciências Sociais Aplicadas, Ciências Humanas e Ciências Exatas e da Terra são as áreas que apresentam as maiores proporções de evasão na UFU. Ao analisar as médias por área, verifica-se que as áreas Ciências Agrárias, Ciências Biológicas, Engenharias, Ciências Exatas e da Terra e Ciências da Saúde, que são as áreas tradicionalmente mais concorridas nos processos seletivos, apresentam aumentos significativos nos percentuais de alunos evadidos após o SISU.

Já as áreas de Ciências Humanas, Linguística, Letras e Artes e Ciências Sociais Aplicadas, que são áreas menos concorridas nos processos seletivos, apresentaram reduções significativas nos percentuais de alunos evadidos. Esses resultados permitem inferir que a adoção do SISU pode ter afetado a evasão na UFU, mas os impactos são diversos, conforme as áreas de conhecimento, ou, talvez, conforme o curso.

Um aspecto que deve ser considerado é que a própria UFU percebe a importância de se acompanhar indicadores de evasão dentro da instituição, seja pelo aspecto acadêmico, seja pelo aspecto pessoal do aluno, oferecendo apoio psicológico e social aos alunos, buscando revisar os conteúdos pedagógicos dos cursos oferecidos e oferecendo programas como o PROSSIGA para melhoria contínua dos professores (MELO; NAVES, 2015).

De forma complementar, a UFU também busca diminuir o número de vagas ociosas, realizando processos seletivos específicos para o preenchimento destas vagas, mediante a possibilidade de transferência interna (dentro de cursos que sejam 
correlatos) ou externa (de outra instituição para a UFU). Em todos os casos há regras e condições específicas para o preenchimento destas vagas.

Outro ponto importante que deve ser considerado é que o SISU permite uma mobilidade maior ao aluno, na medida em que permite que o mesmo possa escolher duas opções de curso para concorrer, optado dessa forma pela escolha do curso que melhor se adeque a sua realidade, desde que consiga aprovação no processo seletivo.

A natureza em que o estudo da evasão está inserido pode ser considerada um campo vasto e complexo, o qual envolve questões pedagógicas, psicológicas, sociais, políticas, econômicas, administrativas, entre outras. Corroborando esse entendimento, Silva Filho et al (2007) salientam que o fato de se querer minimizar frequentemente as razões da evasão, apontando como regra geral a falta de recursos financeiros do aluno como a principal causa para a interrupção de seus estudos, não é completamente verdadeira.

Assim, é importante que se priorize também a compreensão das questões de ordem acadêmica, como as expectativas do aluno em relação ao curso ou à instituição que podem encorajá-lo ou desestimulá-lo a priorizar a conclusão do seu curso. Outro ponto importante a ser observado é que a evasão deve ser abordada por diversos aspectos.

Esses aspectos vão desde elementos que envolvam as características do aluno evadido, passam pela verificação dos conteúdos pedagógicos e outros que sejam pertinentes aos cursos onde a evasão mais ocorre. De posse desse conhecimento, transformá-lo em ações de planejamento e gestão por parte da administração superior, é tarefa obrigatória. Justificando, dessa maneira, a realização de investimentos no esforço de reduzir a evasão no âmbito universitário, reduzindo as perdas e o desperdício de dinheiro público nos diversos segmentos econômico-sociais e acadêmicos (SANTOS BAGGI; LOPES, 2011).

Esse conjunto deve trabalhar objetivando a busca de ferramentas e soluções que possam minimizar ou evitar o fenômeno da evasão, oferecendo suporte e a atuação necessária para que o aluno possa completar o ciclo de aprendizado.

O presente estudo está sujeito a algumas limitações. A primeira delas se refere ao fato de investigar uma única instituição, dessa forma os dados não podem ser generalizados para outros contextos ou realidades. Também é importante ressaltar que o estudo focou as proporções de evasão antes e após a adoção do SISU e não as taxas de evasão, assim, aspectos como aumento na oferta de vagas por parte da UFU no 
período investigado ou alterações nas normas internas podem ter afetado as proporções estudadas.

Sugere-se para futuros trabalhos abordar o domicílio de origem dos alunos e o seu comportamento, em termos de evasão, antes e após a adoção do SISU. Considerando o domicílio de origem do candidato também pode ser verificado se os alunos evadidos estão mais próximos ou distantes do local onde residem, podendo inferir se este é um fator que afeta a evasão.

Outro fator que pode ser abordado em futuras pesquisas é o perfil do aluno evadido, considerando não somente informações de coeficiente de rendimento acadêmico, mas também fatores de caráter socioeconômico, identificando por meio de ferramentas estatísticas alunos que possam estar caminhando para a evasão, pela análise das variáveis colocadas, agindo assim preventivamente.

Sun Tzu disse: "Nada é mais difícil do que a arte das manobras, e mais difícil ainda é tornar direto o percurso aparentemente desviado e transformar os infortúnios em vantagens." Os administradores do ensino superior têm essa capacidade, ou possuem dados que possam dar condições para tomada de decisão? Se não, eles devem adquiri-la, enfrentar e resolver, da melhor maneira, as dificuldades inerentes à gestão.

\section{Referências}

BARDAGI, M. P.; HUTZ, C. S.; "Não havia outra saída": percepções de alunos evadidos sobre o abandono do curso superior. Psico-USF (Impr.), Itatiba, v. 14, n. 1, abril, $2009 . \quad$ Disponível em: $<$ http://www.scielo.br/scielo.php?script=sci_arttext\&pid=S1413-

82712009000100010\&lng=en\&nrm=iso>. Acesso em: 05 abr. 2015.

BEUREN, I. M. (org). Como Elaborar Trabalhos Monográficos em Contabilidade: Teoria e prática. 4 ed. São Paulo: Atlas, 2009

BRASIL. Ministério da Educação e do Desporto. Secretaria de Educação Superior. Comissão Especial Sobre a Evasão nas Universidades Públicas Brasileiras. Diplomação, retenção e evasão nos cursos de graduação em instituições de ensino superior públicas. Brasília, outubro de 1997. Disponível em:

<http://www.udesc.br/arquivos/id_submenu/102/diplomacao.pdf>. Acesso em: 18 abr. 2015. 
BRASIL. Portaria Normativa. Portaria Normativa $\mathbf{n}^{\mathbf{0}}$ 2, de 26 de janeiro de 2010. Institui e regulamenta o Sistema de Seleção Unificada, sistema informatizado gerenciado pelo Ministério da Educação, para seleção de candidatos a vagas em cursos de graduação disponibilizadas pelas instituições públicas de educação superior dele participantes. Diário Oficial da União. Brasília, 2010.

BRASIL. Secretaria de Educação Superior. Plano de Desenvolvimento Institucional PDI: diretrizes para elaboração. Brasília: MEC/ SESu, jun. 2002.

BRASIL. Quem pode se inscrever no SISU 1\%2015. Disponível em: <http://SISU.mec.gov.br/SISU\#quem_pode>. 2015. Acesso em 22/03/2015 as 16:55

BRASIL. Sistema de Seleção Unificada. Disponível em: http://SISU.mec.gov.br. Acesso em: 24 de fevereiro de 2013a.

BRASIL. SISU avança na democratização do acesso a universidade. Disponível em: <http://www.dilma.com.br/site/destaques/SISU>. Acesso em: 24 fev. 2013 b.

CHIAVENATO, I. - Introdução à Teoria Geral da Administração: uma visão abrangente da moderna administração das organizações. $7^{\mathrm{a}}$ ed. rev. e atual. - Rio de Janeiro: Elsevier, 2003 - 12 $2^{\mathrm{a}}$ Reimpressão.

CUNHA, J. V. A.; DE LUCA, M. M. M.; LIMA, G. A. S. F.; CORNACCHIONE Jr., E. B.; OTT, E. Quem está ficando para trás? Uma década de evasão nos cursos brasileiros. Repec - Revista de Educação e Pesquisa em Contabilidade, Brasília, v. 9, n. 2, art. 1, p. 124-142, abr./jun. 2015.

FURTADO, V. V. A.; ALVES, T. W. Fatores determinantes da evasão universitária: uma análise com alunos da UNISINOS. Contextus Revista Contemporânea de Economia e Gestão, vol. 10, n. 2, jul/dez, 2012.

GAIOSO, N. P. L. O fenômeno da evasão escolar na educação superior no Brasil. 2005. 75 f. Dissertação (Mestrado em Educação) - Programa de Pós-Graduação em Educação da Universidade Católica de Brasília, Brasília, 2005.

GIL, A.C. Como Elaborar projeto de Pesquisa. 4 ed. São Paulo: Atlas 2002. p.159

MELO, G.F.; NAVES, M.L.P. Retenção e evasão: desafios para a gestão da educação superior. Disponível em: <http://www.aforges.org/wp-content/uploads/2016/11/10Geovana-Melo-et-al_Retencao-e-evasao.pdf>. Acesso em: 20 mar 2017.

MERCURI, E. e POLYDORO, S. A. J. (2004). "O compromisso com o curso no processo de permanência/evasão no Ensino Superior: algumas contribuições". In: MERCURI, E. e POLYDORO, S. A. J. (orgs.). Estudante universitário: características e experiências de formação. Taubaté, SP: Cabral Ed. e Livraria Universitária.

MOEHLECKE, S.; CATANI, A. M. Reforma e Expansão do Acesso ao Ensino Superior: balanço e proposições. In: Política para as Instituições Federais de Ensino 
Superior (Ifes). In: Políticas de acesso e expansão da educação superior: concepções e desafios / OLIVEIRA, João Ferreira de et al. - Brasília: INEP 2006.

NOGUEIRA, D. UFU lança programa para reduzir em $40 \%$ a retenção e evasão escolar. Correio de Uberlândia, Uberlândia, 30 jul. 2015, Caderno Cidade e Região. Disponível em: <http://www.correiodeuberlandia.com.br/cidade-e-regiao/ufu-lancaprograma-para-reduzir-em-40-a-retencao-e-evasao-escolar/>. Acesso em: 15 out 2015.

SANTOS BAGGI, C. A.; LOPES, D. A. Evasão e avaliação institucional no ensino superior: uma discussão bibliográfica. Avaliação (Campinas), Sorocaba, v. 16, n. 2, p. 355-374, July 2011. Disponível em

$<$ http://www.scielo.br/scielo.php?script=sci_arttext\&pid=S1414-

$40772011000200007 \& \operatorname{lng}=$ en\&nrm=iso>. Acesso em: 28 jun. 2015

SILVA FILHO, R. L. L.; MOTEJUNAS, P. R.; HIPOLITO, O.; LOBO, M. B. C. M. A evasão no ensino superior Brasileiro. Revista cadernos de pesquisa. v. 37. n. 132. setdez. 2007. 641-659 p.

TZU, S. A Arte da Guerra. Coleção a obra-prima de cada autor. Sun Tzu -Texto Integral - Editora Martin Claret. Tradução Pietro Nassetti - 3ª Edição - Impresso 2008 $7^{\mathrm{a}}$ Reimpressão. São Paulo - SP

ANUÁRIO 2014 - ANO BASE 2013. Uberlândia, MG: Universidade Federal de Uberlândia, $2015 . \quad$ Disponível em: <http://www.ufu.br/sites/www.ufu.br/files/Anuario_2014_-_ano_base_2013.pdf>.

Acesso em: 20 abr. 2015.

\section{Como referenciar este artigo:}

BARBOSA, João Paulo Gomes. A Adoção do SISU e a Evasão na Universidade Federal de Uberlândia. Revista Ibero-Americana de Estudos em Educação, Araraquara, v. 12, n. 2, p. 708-721, 2017. Disponível em: <http://dx.doi.org/10.21723/riaee.v12.n2.8352>. E-ISSN: 1982-5587.

Recebido em: 26/07/2016

Aprovação final em: 13/03/2017 